\title{
ADRENAL VIRILISM. II. METABOLIC STUDIES ${ }^{1}$
}

\author{
By JOSEPH W. JAILER,2 JEAN LOUCHART,3 AND GEORGE F. CAHILL
}

\author{
(From the Departments of Medicine, Obstetrics and Gynecology, and Urology, Columbia Uni- \\ versity College of Physicians and Surgeons and the Presbyterian Hospital, \\ New York, N. Y.)
}

(Submitted for publication June 25, 1952; accepted July 31, 1952)

\section{INTRODUCTION}

The clinical syndrome of virilism is well known and has been adequately described in the literature. In the female, when the syndrome is present at birth, the picture is that of pseudohermaphroditism, occasionally of such degree that genetic females are mistaken for males until gonadal biopsy reveals the presence of ovarian structures. When the syndrome develops later in childhood the features of virilism are superimposed upon normal female genitalia. In the male child, precocious puberty ensues. In all the children involved, there is ample evidence of excessive androgenic secretion; growth becomes accelerated; the skeleton matures early; there occurs enlargement of the clitoris in the female and of the penis in the male; and varying degrees of hirsutism and acne are encountered. The most common abnormality encountered in this syndrome is bilateral adrenal hyperplasia.

A rare variant of this condition occurs in newborn infants where in addition to the signs of virilism there is evidence of impaired ability to maintain normal serum concentrations of sodium and chloride. Such infants exhibit evidence of adrenal cortical insufficiency only in respect to salt and water metabolism. Many of the children in the past probably succumbed before the diagnosis was made. With recent advances in our knowledge of electrolyte metabolism, this clinical entity is being recognized more readily, and a gratifying response to therapy has been encountered.

The steroidal content of the urine in adrenal virilism has been the subject of intense investigation (1-9). The 17-ketosteroids and androgens are invariably elevated. The estrogen content of

1 Aided by a Grant from the American Cancer Society as recommended by the Committee on Growth, National Research Council.

2 Damon Runyon Senior Clinical Research Fellow.

${ }^{3}$ Squibb Fellow in Medicine. the urine is also increased $(10,11)$. Pregnanediol, pregnanetriol and other similar pregnane derivatives have also been isolated from the urine of patients with this condition $(2,7)$. The "corticoids" are usually normal but an occasional elevated value has been reported. It is this lack of increased production of the steroids, which are excreted as corticoids, which probably accounts in part for the difference in signs and symptoms of this condition as contrasted to the Cushing syndrome.

The adrenal cortices of patients with the adrenogenital syndrome appear to be secreting excessive amounts of androgen. Andrenocorticotropin has been administered to such patients in an attempt to ascertain how such adrenals respond to further stimulation (12-14). The purpose of this study was to elucidate, if possible, the underlying metabolic defect in adrenal hyperplasia and virilism.

\section{METHODS AND MATERIALS}

Seven patients with documented adrenogenital syndrome and proven bilateral adrenal hyperplasia were selected for these experiments. One male patient, aged two and a half years, presented the combined picture of virilism and "Addisonian-like symptoms"; the remaining six, ranging in age from 10 to 17 years, were female pseudohermaphrodites without abnormalities in sodium metabolism. To approximate a constant sodium chloride intake, the patients were placed on the Hospital salt-poor diet which has been designed to provide $0.5 \mathrm{Gm}$. of sodium daily and were given a measured 4 to $5 \mathrm{Gms}$. of added salt, so that the variations in the sodium chloride content of the diet would be reflected in but minor differences in the over-all sodium chloride intake. An indwelling catheter was inserted into the two and a half year old boy in order to insure complete urine collections. After a suitable control period, ACTH ${ }^{4}$ in four divided daily dosages was administered to each patient for a three-day period.

The 17-ketosteroids were determined by the HoltorffKoch (15) modification of the Zimmerman reaction; the formaldehydogenic steroids by the method of Daughaday,

4 The ACTH was kindly supplied by Armour Laboratories and the cortisone and compound $\mathrm{F}$ by Merck, Inc. 
Jaffe and Williams (16) as modified by Mason (17). For this procedure, an aliquot of the 24-hour urine specimen was acidified to $\mathrm{pH} 1$ and allowed to stand at room temperature overnight before extraction with chloroform. Glucuronidase hydrolysis was not performed initially since the study was embarked upon before this method had been perfected. Subsequently, it seemed desirable to obtain strictly comparable data; hence this modification was not introduced. The analysis of urinary and serum sodium and potassium was performed by flame photometry. Completeness of the urine collections was checked by creatinine determinations.

After the three-day course of ACTH the patients were given cortisone or compound $\mathrm{F}^{4}$ in an attempt to cause a reversal of the clinical state. These results have been presented in a separate publication (Jailer, Louchart, and Cahill [18]).

\section{RESULTS}

\section{Virilism with Addisonian-like symptoms}

Patient L. Y. was a two and a half year old male who in addition to virilism demonstrated "Addisonian-like symptoms." In order to maintain his serum sodium at normal levels it was necessary to administer $5 \mathrm{mg}$. per day of desoxycorticosterone

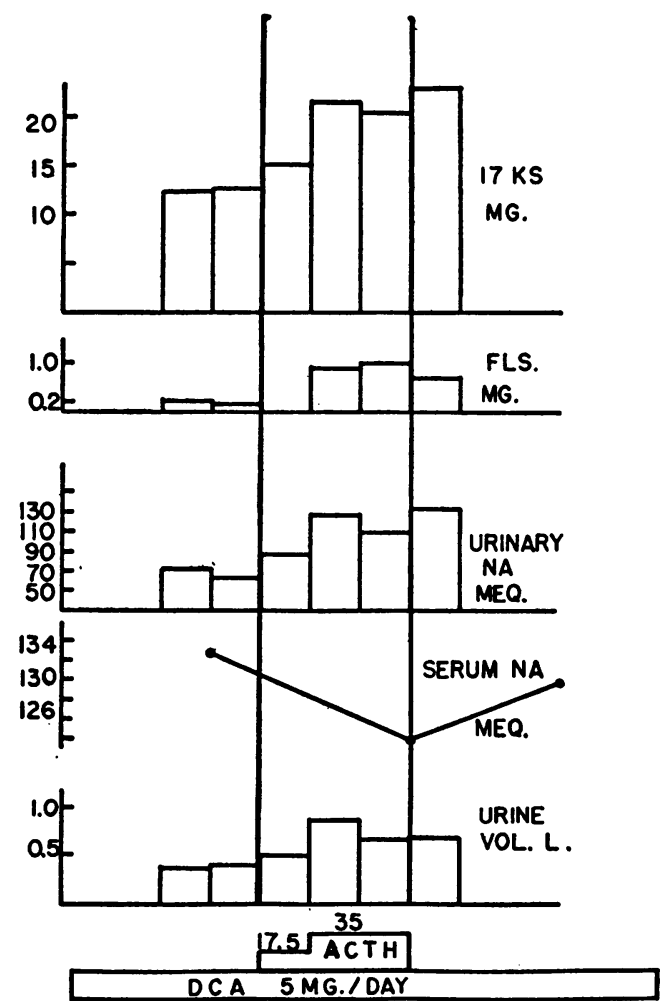

Fig. 1. The EFfect of ACTH on 17-Ketosteroids (17-KS), Formaldehydogenic Steroids (FLS), Sodium and Urine Volume in Patient L. $Y$.

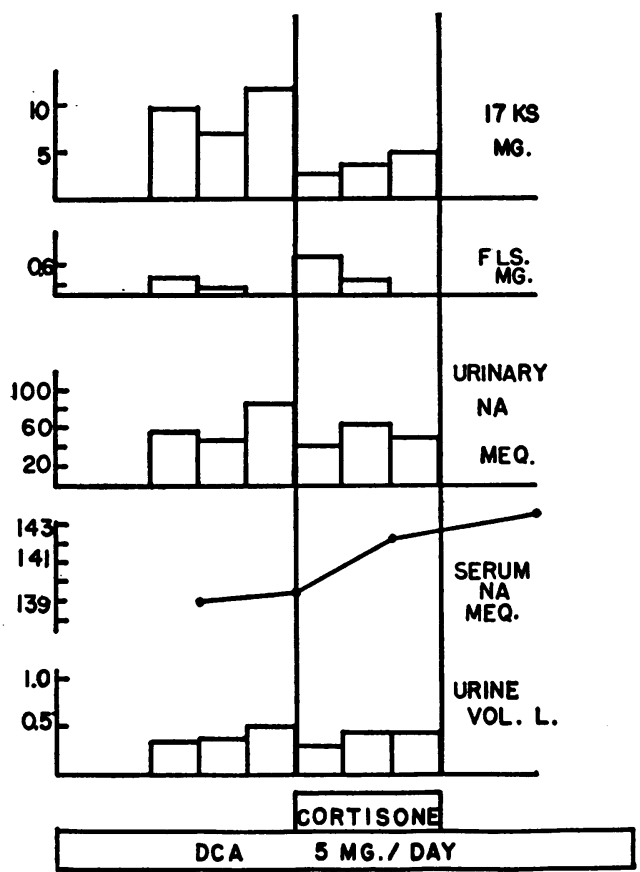

Fig. 2. The Effect of Cortisone on 17-KetosteroIDS (17 KS); ForMaldehydogenic SteroIdS (FLS), Sodium and Urine Volume in Patient L. Y.

acetate (DCA) intramuscularly and supplement his diet with $5 \mathrm{Gms}$. of added salt. Throughout the experimental period he was maintained on this regimen. The administration of a total of $17.5 \mathrm{mg}$. of ACTH for one day and $35 \mathrm{mg}$. of $\mathrm{ACTH}$ per day in divided doses for two days more resulted in a marked increase in urine volume and a diuresis of sodium. This was accompanied by a decline in his serum sodium from 133 to 124 $\mathrm{mEq}$. within three days, loss of a pound in weight and a blood pressure fall from 120/90 to 90/60; consequently the experiment was terminated. Thus, evidence of adrenal cortical insufficiency supervened in spite of the fact that the urinary $17-$ ketosteroids and corticoids increased as a result of ACTH stimulation (Figure 1).

The subsequent administration of cortisone was without effect on the excretion of sodium but caused a marked decline in urinary 17 -ketosteroids (Figure 2). While continuing cortisone it was possible gradually to withdraw the DCA and for more than a year this patient was maintained on as little as 12.5 cortisone per day intramuscularly with 5 Gms. added salt. Subsequent withdrawal of cortisone resulted in an exacerbation of all his 
symptoms. At present he is continuing to receive daily cortisone.

\section{Pure virilizing syndrome}

Six pseudohermaphrodites, of which only four were on a constant salt intake, were given 75 to $100 \mathrm{mg}$. per day of Armour ACTH. In only one of these four patients ( $T . K$.) was there minimal evidence of sodium retention as a result of the ACTH administration. In the other three, ACTH administration had no significant effect on sodium excretion (Figure 3). There was no suppression of urinary output during this period so that this lack of sodium retention could not be due to inhibition of the usual effects of ACTH by posterior pituitary contamination of the hormone preparation. Serum sodium levels were unaffected. There was no transient potassium diuresis. The administration of ACTH did not result in an increase in the excretion of the formaldehydogenic steroids (Figure 4) in six patients, and in only one patient (C. B.) was there a twofold increase in these urinary steroids. On the other hand, the administration of $100 \mathrm{mg}$. per day of the same batch of ACTH to a normal individual resulted in a fourfold increase in formaldehydogenic steroids. A clitorectomy under general anesthesia was subsequently performed on patient
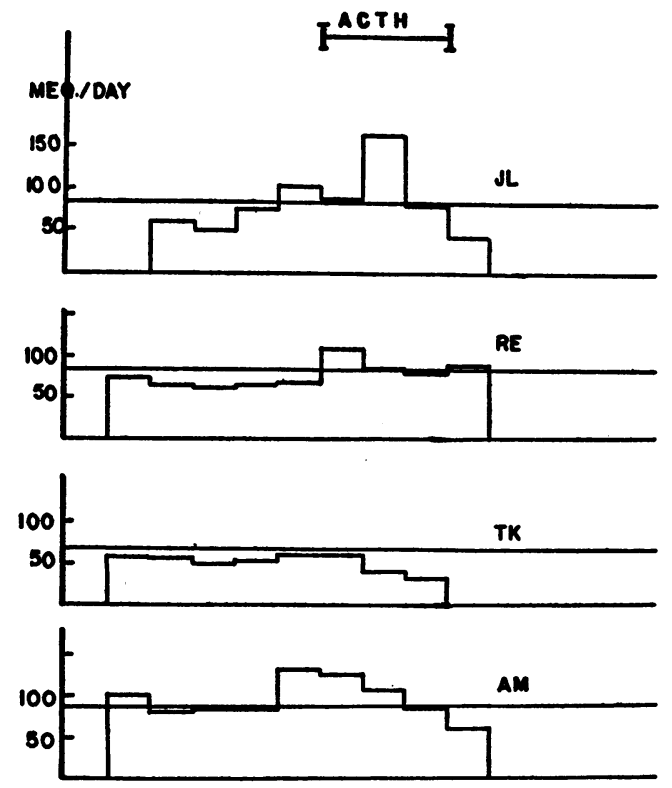

Fig. 3. The Efrect of ACTH on the Urinary ExCRETION OF SODIUM

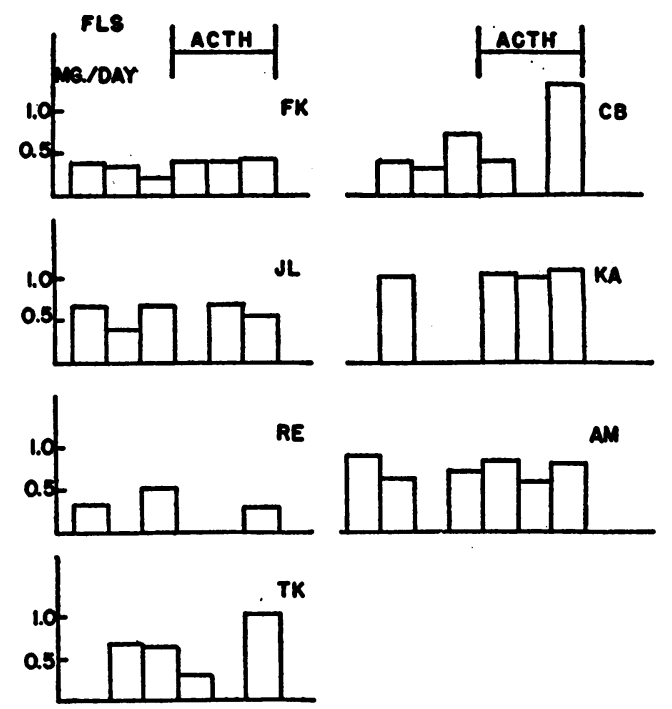

Fig. 4. The Effect of ACTH on the Excretion of FORMALDEH YDOGENIC STEROIDS

Patient KA was a pseudohermaphrodite who was not included in the balance studies.

C.B. and on the first two days postoperatively there was no rise in the urinary corticoids.

In only one of the four patients was there a marked decrease in circulating eosinophils during ACTH administration (Figure 5). This decrease in eosinophils has been amply shown to occur as a result of adrenal stimulation.

It was only in the sphere of urinary neutral 17ketosteroids that there was evidence of a response

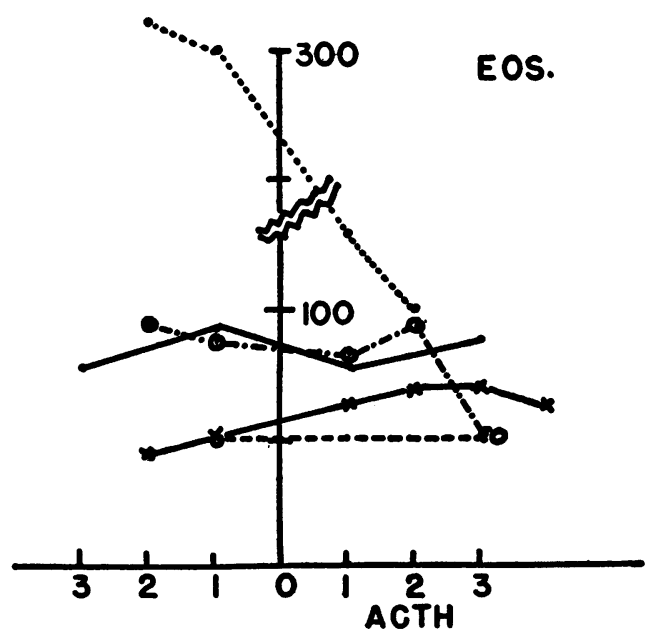

Fig. 5. The Efrict of ACTH on Circulating EOSINOPHILS

The days to the left are control days. 

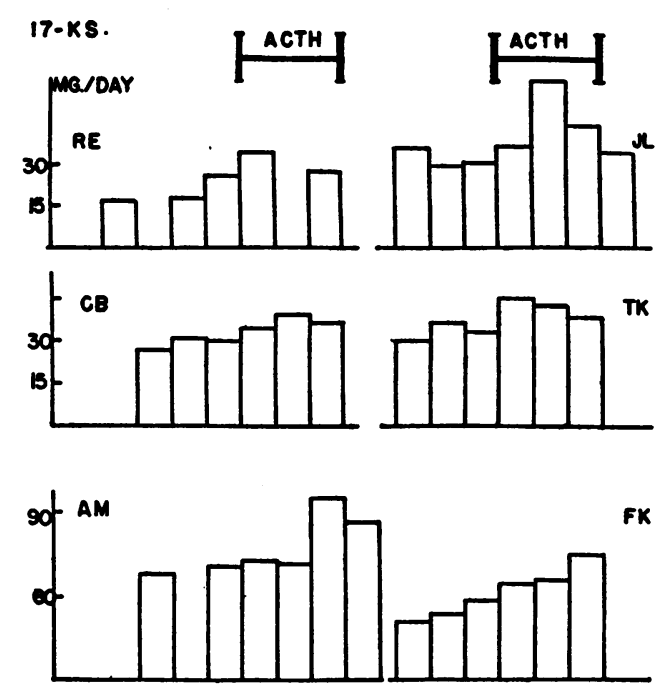

Fig. 6. The Effect of ACTH on the Urinary ExCRETION OF 17-KETOSTEROIDS (17 KS)

to pituitary stimulation. The elevated 17 -ketosteroid values were further increased as a result of ACTH stimulation (Figure 6).

\section{DISCUSSION}

The administration of cortisone to patients with virilism due to adrenal hyperplasia results in a prompt decline in the urinary 17 -ketosteroid excretion values. The mechanism for this effect is apparently due to the inhibition of pituitary ACTH secretion $(11,13,18)$. Animal experiments have amply demonstrated that excessive cortisone administration can inhibit ACTH production (19).

The administration of ACTH to normal individuals results in adrenal stimulation as manifested by sodium retention, fall in circulating eosinophils, and increase in corticoids and 17ketosteroids $(20,21)$. On the other hand, in patients with adrenal virilism, the injection of ACTH causes only the characteristic rise in urinary 17 -ketosteroids but has minimal effects on corticoid excretion, eosinophils and salt retention. Bartter and his colleagues (13) have claimed that instead of the usual increased nitrogen excretion, patients with adrenal virilism may even retain nitrogen when given ACTH. Apparently, only the androgenic component of the adrenal can be stimulated in this disease.

In the one patient in whom the virilizing syndrome was associated with Addisonian-like symp- toms the administration of ACTH was accompanied by increased sodium excretion as well as a rise in formaldehydogenic steroids. The fact that sodium diuresis ensued in spite of the continued administration of DCA suggests that a substance secreted by the adrenals may be considered a DCA antagonist in its overall effect, and is excreted in the "formaldehydogenic" fraction. The rise in formaldehydogenic steroids is in contrast with what obtains in the pure adrenal virilism, where these steroids are not increased by ACTH administration. It would appear that exogenous cortisone administration, by suppressing pituitary ACTH secretion, indirectly inhibits the production of this salt-losing steroid by the adrenal and therefore it is no longer necessary to administer DCA in order to maintain sodium balance.

There has been some speculation as to the underlying biochemical defect present in adrenocortical hyperplasia with virilism. The most obvious explanation would be that the adrenal cortex is secreting excessive amounts of androgens in addition to normal quantities of corticosteroids. However, if this were true it might be expected that further stimulation of such adrenals should result in increases in all moieties of adrenal steroids. However, this is not the case $(13,14)$. The administration of ACTH results in increases in only the androgenic components.

The administration of cortisone or compound $F$ to patients with Addison's disease results in a rise in urinary 17-ketosteroid excretion (22) and therefore it may be assumed that these corticosteroids can be degraded to $17-$ ketosteroids. It may be postulated that in the hyperplastic adrenal of the adrenogenital syndrome the degradation of cortisone or compound $\mathrm{F}$ is deflected toward the 17ketosteroid complex resulting in a temporary hypoadrenalism. The pituitary would in turn secrete excessive amounts of ACTH in an attempt to maintain circulating corticosteroids at a normal level. As a result of this, excessive amounts of androgens would be formed as a result of excessive degradation of the corticosteroids to the C-19 steroids. Therefore, any increment of ACTH would result in increases in androgenic secretion accompanied by no or minimal rises in corticosteroid liberation.

It is also tempting to speculate that the mechanism in Cushing's syndrome is somewhat different. 
This syndrome is one of hyperadrenalism (23). In this condition, also, there is evidence that excessive quantities of ACTH are being secreted, but the degradation mechanism is different so that the corticosteroids are not converted to androgens.

\section{SUM MARY}

The administration of ACTH for three days to one patient with virilism and "Addisonian-like symptoms" resulted in an increased excretion of urinary sodium and a decline in serum sodium from 133 to $124 \mathrm{mEq}$. in spite of definite evidence of adrenal stimulation. The stimulation of the adrenals of patients with the pure virilizing syndrome was accompanied by increased 17-ketosteroid excretion; however, there was no significant sodium retention, fall in circulating eosinophils or rise in formaldehydogenic steroids.

\section{REFERENCES}

1. Callow, N. H., and Crooke, A. C., Diagnosis of adrenal tumors. Estimation of 17 -ketosteroids in urine. Lancet, 1944, 246, 464.

2. Butler, G. C., and Marrian, G. F., The isolation of pregnane-3,17,20-triol from the urine of women showing the adrenogenital syndrome. J. Biol. Chem., 1937, 119, 565.

3. Engstrom, W. W., Mason, H. L., and Kepler, E. J., Excretion of neutral 17-ketosteroids in adrenal cortical tumor and feminine pseudohermaphroditism with adrenal cortical hyperplasia. J. Clin. Endocrinol., 1944, 4, 152.

4. Hain, A. M., Adrenal tumours and pseudo-hermaphroditism: a hormone study of cases. J. Path. \& Bact., 1947, 59, 267.

5. Lieberman, S., Dobriner, K., Hill, B. R., Fieser, L. F., and Rhoads, C. P., Studies in steroid metabolism. II. Identification and characterization of ketosteroids isolated from urine of healthy and diseased persons. J. Biol. Chem., 1948, 172, 263.

6. Mason, H. L., Urinary steroids in adrenal disease and the metabolism of adrenal hormones. Recent Progress in Hormone Research, Pinus, G., editor, Academic Press, New York, 1948, Vol. 3, p. 103.

7. Miller, A. M., and Dorfman, R. I., Metabolism of the steroid hormones : isolation of 13 steroid metabolites from a patient with (probable) adrenal hyperplasia. Endocrinology, 1950, 46, 514.

8. Talbot, N. B., Butler, A. M., and MacLachlan, E. A., Alpha and beta neutral ketosteroids (androgens). Preliminary observation on their normal urinary excretion and the clinical usefulness of their assay in differential diagnosis. New England J. Med., 1940, 223, 369.

9. Talbot, N. B., Butler, A. M., and Berman, R. A., Adrenal cortical hyperplasia with virilism: diagnosis, course and treatment. J. Clin. Invest., 1942, 21, 559.

10. Jailer, J. W., A fluorometric method for the clinical determination of estrone and estradiol. J. Clin. Endocrinol., 1948, 8, 564.

11. Wilkins, L., Lewis, R. A., Klein, R., Gardner, L. I., Crigler, J. F., Jr., Rosemberg, E., and Migeon, C. J., Treatment of congenital hyperplasia with cortisone. J. Clin. Endocrinol., 1951, 11, 1.

12. Lewis, R. A., and Wilkins, L., The effect of adrenocorticotrophic hormone in congenital adrenal hyperplasia with virilism and in Cushing's syndrome treated with methyl testosterone. J. Clin. Invest., 1949, 28, 394.

13. Bartter, F. C., Albright, F., Forbes, A. P., Leaf, A., Dempsey, E., and Carroll, E., The effects of adrenocorticotrophic hormone and cortisone in the adrenogenital syndrome associated with congenital adrenal hyperplasia : an attempt to explain and correct its disordered hormonal pattern. J. Clin. Invest., 1951, 30, 237.

14. Jailer, J. W., Recent studies on adrenal hyperplasia. Tr. New York Acad. Sc., Series II, 1951, 13, 262.

15. Holtorff, A. F., and Koch, F. C., The colorimetric estimation of 17 -ketosteroids and their application to urine extracts. J. Biol. Chem., 1940, 135, 377.

16. Daughaday, W. H., Jaffe, H., and Williams, R. H., Chemical assay for "cortin." Determination of formaldehyde liberated on oxidation with periodic acid. J. Clin. Endocrinol., 1948, 8, 166.

17. Mason, H. L., Personal communication.

18. Jailer, J. W., Louchart, J., and Cahill, G. F., Adrenal virilism. I. Treatment and diagnostic considerations. J.A.M.A., 1952, in press.

19. Ingle, D. J., The biologic properties of cortisone: a review. J. Clin. Endocrinol., 1950, 10, 1312.

20. Sprague, R. G., Power, M. H., Mason, H. L., Albert, A., Mathieson, D. R., Hench, P. S., Kendall E. C., Slocumb, C. H., and Polley, H. F., Observations on the physiologic effects of cortisone and ACTH in man. Arch. Int. Med., 1950, 85, 199.

21. Luft, R., Sjögren, B., and Li, C. H., Metabolic studies with ACTH protein. Acta endocrinol., 1950, 5, 327.

22. Jailer, J. W., and Knowlton, A. I., Unpublished data.

23. Albright, F., Cushing's Syndrome: its pathological physiology, its relationship to adreno-genital syndrome, and its connection with the problem of the reaction of the body to injurious agents ("alarm reaction" of Selye), Harvey Lectures, 1942-1943, 38, 123. 